\title{
Analysis on the Current Situation of Social Security for Landless Farmers Under the Background of Urbanization
}

\begin{abstract}
Taipeng Wang*
School of Ethnology and Sociology \& Southwest Minzu Research Institute of Southwest Minzu University, Chengdu 610041, Sichuan Province, China

*Corresponding author: Taipeng Wang, wangtp@swun.edu.cn

Abstract: With the rapid development of China's social economy, the economy of various regions has rapidly improved. At the same time, people are paying more attention to the issue of farmers' social security. In order to realize the rapid development of regional economy and form a relatively stable social order, there is a need to improve the social security system of farmers so as to ensure that more people acquire basic social security rights. On this basis, based on the background of urbanization, this article studies the social security status of landless farmers in R city, and analyzes the old-age security as well as the medical insurance of landless farmers in R city.
\end{abstract}

Keywords: Landless farmers; Old-age security; Medical insurance

Publication date: August 2021; Online publication: August 30, 2021

\section{Introduction}

With the rapid development of China's economy and the acceleration of China's urbanization process, a large number of cultivated lands has been transformed into construction lands, which causes more and more farmers to lose their land and become a special group - landless farmers. The transformation of agricultural lands into industrial lands results in the gradual increase of the numbers of landless farmers. In this context, this article studies the current situation of social security among landless farmers in S village of R city in order to analyze the education, life, employment, and other problems faced by landless farmers, effectively promote the development of urban-rural integration economy, as well as the equalization of social public services. The so-called landless farmers refer to farmers who have lost land management rights due to land acquisition in the process of urbanization in which they have lost the original agricultural land management rights and have not been included in the urban social security system.

2. Analysis on the social security status of landless farmers in $R$ city under the background of urbanization

In order to better research the current situation of social security among landless farmers in R city, analysis had been done from the aspects of old-age security and medical insurance. By interviewing landless farmers in $\mathrm{S}$ village of $\mathrm{R}$ city, as well as sorting out and analyzing the interview data, the problems existing in the social security of landless farmers in $\mathrm{S}$ village of $\mathrm{R}$ city were found.

\subsection{Current situation of old-age security}

Endowment policy is conducive to ensure the reproduction of labor force. Through the establishment of 
personal endowment insurance system, the elderly can retire, and the new growing labor force would be smoothly employed so as to ensure the rationalization of employment structure. Participating in personal endowment insurance means to have an expectation of one's future life at an old age and avoid worries. From the perspective of social mentality, people are more stable and less impetuous, which is conducive to social stability and economic development. In addition, due to the wide coverage and large number of participants of personal endowment insurance, a large amount of endowment insurance funds can be raised in its operation, which can provide a huge source of funds for the capital market especially the endowment insurance mode of fund system. The accumulation of funds in individual accounts is calculated in decades, which makes the scale of endowment insurance fund larger and provides more funds for the market. The operation and utilization of scale funds are conducive to the macro-control of national economy.

In terms of old-age security, R city now mainly adopts the joint financing of individuals, collectives, and the government. Farmers voluntarily participate in the insurance. The fees that individuals and collectives should pay are deducted from the compensation for land acquisition and demolition as well as resettlement fees. After landless farmers reach the age of 60 , they can receive a certain pension according to a certain standard every month. However, only $21 \%$ of the landless farmers in this village applied for endowment insurance. It is not difficult to appreciate that the popularity of endowment insurance in this village is not high. At present, $79 \%$ of the landless farmers in this village have not applied for endowment insurance. It can be understood that the awareness of landless farmers in this village is not high, and some of them have not even heard of endowment insurance.

\subsection{Current situation of medical insurance}

In terms of medical insurance, $\mathrm{R}$ city began to implement the New Rural Cooperative Medical Scheme in 2012. The local raising standard was raised to 280 yuan per person per year of which 50 yuan was paid by individual farmers, 110 yuan was subsidized by the local finance per person per year, and 120 yuan was subsidized by the central finance per person per year. However, only $43 \%$ of the landless farmers in this village had taken out their medical insurance, and $70 \%$ of them have only taken out their medical insurance for hospitalization. This shows that there are problems in the implementation of medical insurance for landless farmers in $\mathrm{R}$ city in addition to many uninsured people.

Medical insurance is the inevitable result of social progress and production development. Conversely, the establishment and improvement of the medical insurance system would further promote social progress and production development. On the one hand, medical insurance relieves worries and allows the workers to work at ease, which can improve labor productivity and promote the development of production. On the other hand, it also ensures the workers' physical and mental health as well as the normal reproduction of the labor force. Hence, it is necessary to popularize medical insurance for the landless farmers in this village.

\section{Problems of social security for landless farmers in $\mathbf{R}$ city}

\subsection{Insufficient investment of endowment insurance for landless farmers}

In the implementation of social security, the investment of $\mathrm{R}$ city in the social security fund for the elderly landless farmers is insufficient. In the face of aging population, the importance of social security system for landless farmers is gradually improving. Through financial budget arrangements at all levels, it is conducive to the total expenditure of social security, and it strengthens the investment of social security funds for landless farmers in $\mathrm{R}$ city. In this system, the financial expenditure of social security is an important standard to reflect the government's public property expenditure. Although the government's investment in social security for the elderly landless farmers in R city has been continuously strengthened, it has not achieved the expected effect. 
With the rapid development of social economy and the continuous improvement of social facilities, landless farmers have higher requirements for the quality of life. So far, the investment in social security for the elderly is insufficient. For a long time, there have been many reasons for the lack of investment in social security for landless farmers in R city. Firstly, the government does not have a perfect distribution system, and the fund investment in social security for landless farmers is active. Secondly, the fund allocation of social security for landless farmers is unreasonable. There is a huge difference between ideal allocation of funds and reality. The government does not specify clear provisions which leads to difficulties in carrying out social security work for the elderly landless farmers, resulting in a waste of capital flow and a lack of funds for social security. In fact, the main problem is that $\mathrm{R}$ city has insufficient investment in social security for the elderly landless farmers in addition to the government that lacks corresponding policies and measures, which leads to the stagnation of social security system for elderly landless farmers as well as affecting the future social and economic development of $\mathrm{R}$ city.

\subsection{Malpractice of medical insurance for farmers in rural areas}

As a prefecture-level city, R city began to implement the New Rural Cooperative Medical Scheme in 2012, which has been strongly supported by the local people. However, there are many problems in the process of implementing this system. For example, medical insurance stipulates that non-serious illnesses and hospitalizations cannot be reimbursed for medical expenses, in addition, the reimbursement ratio is not high so the daily medical care of farmers is not guaranteed. In medical insurance, the main reimbursement is the medical expenses for serious diseases and hospitalizations. Some minor diseases that do not need hospitalizations but require treatment do not belong to the reimbursement scope. The accumulated medical expenses are still a heavy burden for farmers especially for landless farmers. In the long run, the insurance consciousness, the recognition of medical insurance, and the enthusiasm for insurance of landless farmers would be greatly reduced. These are the dilemma of the medical security system of landless farmers in $\mathrm{R}$ city at this stage.

At present, the economy of $\mathrm{R}$ city is still in the primary stage of development, and the government provides only a few jobs for landless farmers. Hence, some young landless farmers choose to work outside in order to make a better living. According to the current policy of the New Rural Cooperative Medical Scheme, farmers who participate in the cooperative medical system need to be treated in the designated city, county, or township hospitals to be able to claim part of their medical expenses. Therefore, landless farmers who have chosen to work outside are not able to receive aid from the rural medical insurance. In addition, in the context of urbanization, the speed and level of R city's economic development are behind other cities where most farmers rely on their own family income for medical expenses in which this is obviously not the case for landless farmers that have lost their stable income. Therefore, the malpractice of medical insurance for landless farmers in $\mathrm{R}$ city is prominent.

\subsection{Imperfect legislation of land expropriation security for landless farmers}

$\mathrm{R}$ city is a prefecture-level city with jurisdiction over one municipal district and 17 counties. In recent years, the population in $\mathrm{R}$ city is increasing, and at the same time, the issue of aging population is much more obvious. Along with the rapid growth of the population, the formation of a competitive relationship between lands exists. However, at this stage, the land expropriation security system of landless farmers in R city lags behind in addition to imperfect laws and regulations; hence, these problems which include the social security problem of landless farmers cannot be solved. Although China has promulgated a series of law and policies such as the social insurance law in order to solve the problems existing in the land expropriation security of landless farmers, some restrictions have been carried out so that the social security work of $\mathrm{R}$ 
city has a certain legal basis. However, the provisions of the law on the protection of land expropriation of landless farmers are imperfect; there are no targeted laws and regulations, as well as mandatory legal effect. If the legitimate interests of landless farmers are infringed, there is no sound legal system to protect them, and landless farmers themselves have no ability to solve the problem, thus it will harm the interests of vulnerable groups. This is an era of increasingly popular law, but through interviews with landless farmers in this village, it is understood that most farmers lack legal awareness.

\section{Suggestions on improving the social security of landless farmers in $\mathbf{R}$ city}

Under the background of urbanization, the problem of social security of landless farmers in R city is more prominent. According to the above analysis of the problems existing in the endowment security and medical insurance of landless farmers in R city, in order to improve the social security of landless farmers in R City, the following aspects can be considered:

\subsection{Realizing the equalization of basic public services}

\subsubsection{Win-win model of economic development and public services}

The development of economy and public services in different ethnic areas have certain characteristics. Dealing with the relationship between economic development and public services is the most basic way to ensure the development of ethnic areas and social security. In regard to this, if $\mathrm{R}$ city wants to achieve the equalization of basic public services, it can build a win-win model of economic development and public services. First of all, the foundation of public service security is the continuous improvement of economy. In order to effectively expand the investment in public services, there is a need to ensure that the economy continues to rise so that the funds obtained can provide better services for the landless farmers in $\mathrm{R}$ city. Only with the rise of the economy, the improvement of public services can be promoted, and vice versa, the basis of public service lays the foundation for economic development. Therefore, in order to change the administrative concept of the government in $\mathrm{R}$ city, there is a need to sort out the correct views of political achievements, as well as constantly increase the assessment and investment in public services from the long-term perspective of ethnic regions so as to achieve a win-win situation of partial regional economic development and public services.

\subsubsection{Reshaping the public service concept of local government}

The government's public service concept in R city is mainly in the common service activities, government staffs around the management, and service work concept. In public service, government staffs are the main force where their own quality and service consciousness would affect the efficiency of public services and the construction of government service-oriented institutions. The concept of public service in $\mathrm{R}$ city has a certain impact on government activities. Therefore, in order to change the government's public service concept in ethnic areas, the concept of serving landless farmers should be formed in the perspective of the interests of landless farmers. In the process of market development, there is a need to give full play to the role of the market in the allocation of resources, create a better market environment, constantly improve and strengthen the efficiency of public services and the publicity of legal knowledge, respectively, as well as ensure the legitimate rights and interests of landless farmers by law.

\subsection{Strengthening the old-age security of landless farmers}

At present, $\mathrm{R}$ city has only a few investments in endowment insurance, so it is necessary to increase the investments in endowment insurance. According to the interview, the number of people handling 
endowment insurance in the village is small where the process is troublesome, and the amount of insurance is small. In regard to this, there is a need to continue to increase the investments in endowment insurance funds. In recent years, all kinds of poverty alleviation operations in $\mathrm{R}$ city have aroused the attention from the society and have made obvious achievements. At the same time, the supervision and audit department of $\mathrm{R}$ city has also carried out the corresponding supervision on the endowment insurance funds, and timely rectified the problems found. In order to fundamentally solve the problems of endowment insurance for landless farmers in $\mathrm{R}$ city, the initiative and creativity of landless farmers should be enhanced while focusing on the self-development and self-accumulation of landless farmers in R city. This would not only reduce poverty in $\mathrm{R}$ city, but it would also create great wealth for the society. Therefore, increasing the investments in endowment insurance and improving the self-reliance ability of landless farmers are beneficial for the sustainable development of the financing of endowment insurance in R city.

\subsection{Improving the medical insurance of landless farmers}

\subsubsection{Reasonable determination of outpatient reimbursement proportion}

It is necessary to reasonably determine the medical reimbursement proportion of landless farmers in $\mathrm{R}$ city who have participated in the New Rural Cooperative Medical Scheme. As a reference, by measuring the value of land for medical insurance, scientific measurement can be carried out to determine the outpatient reimbursement proportion. By appropriately reducing the medical expenses of landless farmers and constantly improving their satisfaction with the New Rural Cooperative Medical Scheme, only then can the landless farmers enjoy the benefits of the system fundamentally.

\subsubsection{Appropriate adjustment of designated hospitals}

$\mathrm{R}$ city needs to improve the medical insurance system of landless farmers especially the reimbursement process of medical expenses. First of all, the number of landless farmers who go out to work needs to be counted. In areas where there are more workers, several hospitals should be designated as medical insurance units. Secondly, the proportion of medical insurance reimbursement should be determined. According to the specific income of migrant workers and the average income of the region, a scientific and reasonable reimbursement amount can be obtained. Through this way, it does not only improve the number of landless farmers to a certain extent, but it also effectively alleviates and solves the medical reimbursement problem of landless farmers that work outside, thus compensating the local economic and social development.

\section{Conclusion}

In the process of urbanization construction of $\mathrm{R}$ city, the social security problems of landless farmers have gradually emerged and are widely concerned. This article studies the corresponding topics of social security for landless farmers in R city in order to provide some enlightenment for a wider range of social security for landless farmers. As far as R city is concerned, the social security problems of landless farmers have a great impact on its social and economic development. Therefore, by fully understanding the real situation of landless farmers as a vulnerable group, establishing a comprehensive social security system, and continuously protecting the economic and social rights of landless farmers, only then the levels of economic and social development can be significantly improved.

\section{Disclosure statement}

The author declares that there is no conflict of interest. 